\title{
BMJ Open Soap versus sanitiser for preventing the transmission of acute respiratory infections in the community: a systematic review with meta-analysis and dose-response analysis
}

Tammy Hoffmann (D), Mina Bakhit (D), Natalia Krzyzaniak (D), Chris Del Mar (D), Anna Mae Scott (D) , Paul Glasziou

To cite: Hoffmann T, Bakhit M, Krzyzaniak N, et al. Soap versus sanitiser for preventing the transmission of acute respiratory infections in the community: a systematic review with meta-analysis and doseresponse analysis. BMJ Open 2021;11:e046175. doi:10.1136/ bmjopen-2020-046175

- Prepublication history and additional supplemental material for this paper are available online. To view these files, please visit the journal online. (http://dx.doi.org/10.1136/ bmjopen-2020-046175).

Received 22 October 2020 Accepted 27 July 2021

Check for updates

(C) Author(s) (or their employer(s)) 2021. Re-use permitted under CC BY-NC. No commercial re-use. See rights and permissions. Published by BMJ.

Institute for Evidence-Based Healthcare, Faculty of Health Sciences and Medicine, Bond University, Gold Coast, Queensland, Australia

Correspondence to Professor Tammy Hoffmann; thoffman@bond.edu.au

\section{ABSTRACT}

Objective To compare the effectiveness of hand hygiene using alcohol-based hand sanitiser to soap and water for preventing the transmission of acute respiratory infections (ARIs) and to assess the relationship between the dose of hand hygiene and the number of ARI, influenza-like illness (ILI) or influenza events.

Design Systematic review and meta-analysis.

Data sources Cochrane Central Register of Controlled Trials (CENTRAL), PubMed, Embase, Cumulative Index of Nursing and Allied Health Literature (CINAHL) and trial registries were searched in April 2020.

Inclusion criteria We included randomised controlled trials that compared a community-based hand hygiene intervention (soap and water, or sanitiser) with a control, or trials that compared sanitiser with soap and water, and measured outcomes of ARI, ILI or laboratory-confirmed influenza or related consequences.

Data extraction and analysis Two review authors independently screened the titles and abstracts for inclusion and extracted data.

Results Eighteen trials were included. When metaanalysed, three trials of soap and water versus control found a non-significant increase in ARI events (risk ratio (RR) $1.23,95 \% \mathrm{Cl} 0.78$ to 1.93 ); six trials of sanitiser versus control found a significant reduction in ARI events (RR $0.80,95 \% \mathrm{Cl} 0.71$ to 0.89 ). When hand hygiene dose was plotted against ARI relative risk, no clear doseresponse relationship was observable. Four trials were head-to-head comparisons of sanitiser and soap and water but too heterogeneous to pool: two found a significantly greater reduction in the sanitiser group compared with the soap group and two found no significant difference between the intervention arms.

Conclusions Adequately performed hand hygiene, with either soap or sanitiser, reduces the risk of ARI virus transmission; however, direct and indirect evidence suggest sanitiser might be more effective in practice.

\section{INTRODUCTION}

Acute respiratory infections (ARIs) cause a substantial annual health burden and much more so in the current COVID-19 pandemic.
Strengths and limitations of this study

Systematic review with meta-analysis and dose-response analysis of randomised controlled trials.

- Additional analysis of a subset of trials from a previously published systematic review and metaanalysis of physical interventions to reduce the spread of respiratory viruses.

- Conclusions are mostly from indirectness evidence, with direct evidence available from only four headto-head trials.

Globally, approximately 4 million deaths per year are caused by ARIs, with the current pandemic leading to just over 4.3 million deaths. ${ }^{12}$ To minimise the potential threat of ARIs to public health, the implementation of effective preventive community-based measures is essential. ${ }^{34}$

Hand hygiene has previously been shown to be an effective intervention that reduces the transmission of the viruses and bacteria that cause ARIs. ${ }^{5}$ It is a low-cost intervention that is applicable in all countries and all settings. Unlike vaccines that are disease specific, hand hygiene has the advantage of being applicable to multiple ARIs. ${ }^{5}$ Despite the effectiveness and worldwide applicability of hand hygiene, important questions for policy and practice remain, such as the doseresponse and relative effectiveness of different materials (alcohol-based hand sanitiser; soap and water). This systematic review aimed to address these questions. This review is an additional analysis of a subset of randomised trials that were included in a large systematic review that addressed all physical interventions (eg, face masks, personal protection, hand hygiene and quarantining) to prevent the transmission of ARIs. ${ }^{5}$ 


\section{METHODS}

We aimed to find, appraise and synthesise studies of the effectiveness of hand hygiene interventions in the community for preventing ARI transmission. For this systematic review, a subset of articles relating to hand hygiene interventions were identified from a recently updated and published systematic review of all physical interventions for preventing ARI transmission. This review was not registered on PROSPERO as this review is an additional analysis of a subset of trials from a published Cochrane systematic review. ${ }^{5}$

\section{Inclusion criteria and study source Participants}

We included studies of participants of any age, gender or condition. Trials in healthcare settings were excluded.

\section{Interventions}

We included studies of interventions that compared a hand hygiene intervention (ie, hand washing with soap and water or hand sanitiser) with a control intervention, or which compared two hand hygiene interventions.

\section{Outcomes}

We only included studies that reported a measure of ARI, such as influenza-like illness (ILI), influenza or respiratory infections, and this was our primary outcome. Studies were also eligible if they reported on ARI consequences (eg, days off work, complications, hospitalisation or death, if clearly reported as consequences of the respiratory illness), and these were our secondary outcomes.

\section{Study design}

Randomised controlled trials (RCTs) and cluster randomised controlled trials (C-RCTs) were eligible.

\section{Search strategy}

RCTs and C-RCTs studying the effectiveness of hand hygiene interventions in the transmission of ARIs were identified from the parent 2020 systematic review. ${ }^{5}$ Studies for that review were identified via a search of the Cochrane Central Register of Controlled Trials, Embase and Cumulative Index of Nursing and Allied Health Literature (CINAHL), covering the dates October 2010 to 9 March 2020. The search string (see online supplemental file 1) was designed for PubMed using the word frequency analyser and then translated for use in other databases using the Polyglot Search Translator. ${ }^{7}$ A backwards and forward citation analysis, using Scopus, was conducted on all new studies retrieved. Search and citation analysis results were screened using the RobotSearch tool to remove all obvious non-RCTs. ${ }^{8}$ While the analysis of the parent review was being conducted, a new Cochrane review of rinse-free handwashing in school and preschool children was published, and we also screened its included studies for possible eligible studies. ${ }^{9}$ Three authors (TH, MB and NK) independently reviewed the titles and abstracts of identified studies to assess eligibility for inclusion. Discrepancies were resolved by consensus.

\section{Screening and data extraction}

Two review authors (MB and NK) independently screened the titles and abstracts for inclusion against the inclusion criteria. One author retrieved the full text and two authors screened the full-texts for inclusion. Any disagreements were resolved by discussion between the authors or with a third author. Data were independently extracted by two authors (MB and NK) on: volume or weight of material (eg, sanitiser or soap) used per person per day and number of handwashes per person per day. When not reported directly, we estimated usage where possible (see table 1). For estimation purposes, we used data on the average amount of material used per person per handwash as reported; if data were not reported, we assumed $0.035 \mathrm{~g}$ of soap or $1.5 \mathrm{~mL}$ of liquid used per handwash. ${ }^{10} \mathrm{~A}$ data extraction form for outcome data was piloted on two studies in the review. The following data were extracted from the parent systematic review ${ }^{5}:(1)$ study characteristics; (2) risk of bias assessments; (3) type of handwashing intervention(s) (eg, soap, sanitiser and gel); and (4) RRs, $\log$ RR and SE values for ARI or ILI or influenza (including the outcome with most events from each study).

\section{Risk of bias assessment}

Risk of bias was assessed with the Cochrane Collaboration's Risk of Bias tool 1. ${ }^{11}$ Author pairs from the parent review independently screened for: the method of random sequence generation and allocation concealment (selection bias), blinding of participants and personnel (performance bias), blinding of outcome assessment (detection bias), outcome reporting (attrition bias) and selective reporting (reporting bias). Disagreements were resolved by discussion or a third assessor. For each item, risk was either 'high', 'low' or 'unclear'.

\section{Data analysis}

To assess the relationship between handwashes per person per day and the number of ARI or ILI or influenza events, we conducted the following analyses: (1) only studies whose number of handwashes could be estimated (regardless of the type of handwash material), subgrouped by the type of handwash material (soap vs sanitiser vs combination of sanitiser and soap) and (2) all studies (whether or not the number of handwashes could be estimated), subgrouped by the type of handwash material (soap vs sanitiser vs combination of sanitiser and soap). We used a $\chi^{2}$ test to test for subgroup interactions. Meta-analyses were conducted using Review Manager 5.4.

We used RRs for results, reporting the number of participants with an event. We undertook meta-analyses where data were sufficient to pool (when $\geq 2$ studies or comparisons reported the same outcome). A random effects model was used because we expected some heterogeneity in the populations, interventions and outcomes of the included studies. The individual was used as the unit of analysis, where possible. However, where data on the number of individuals with primary and secondary outcomes of interest were not available, we extracted and used data for the closest equivalent ratio, for example, a rate ratio based on the ratio of total 


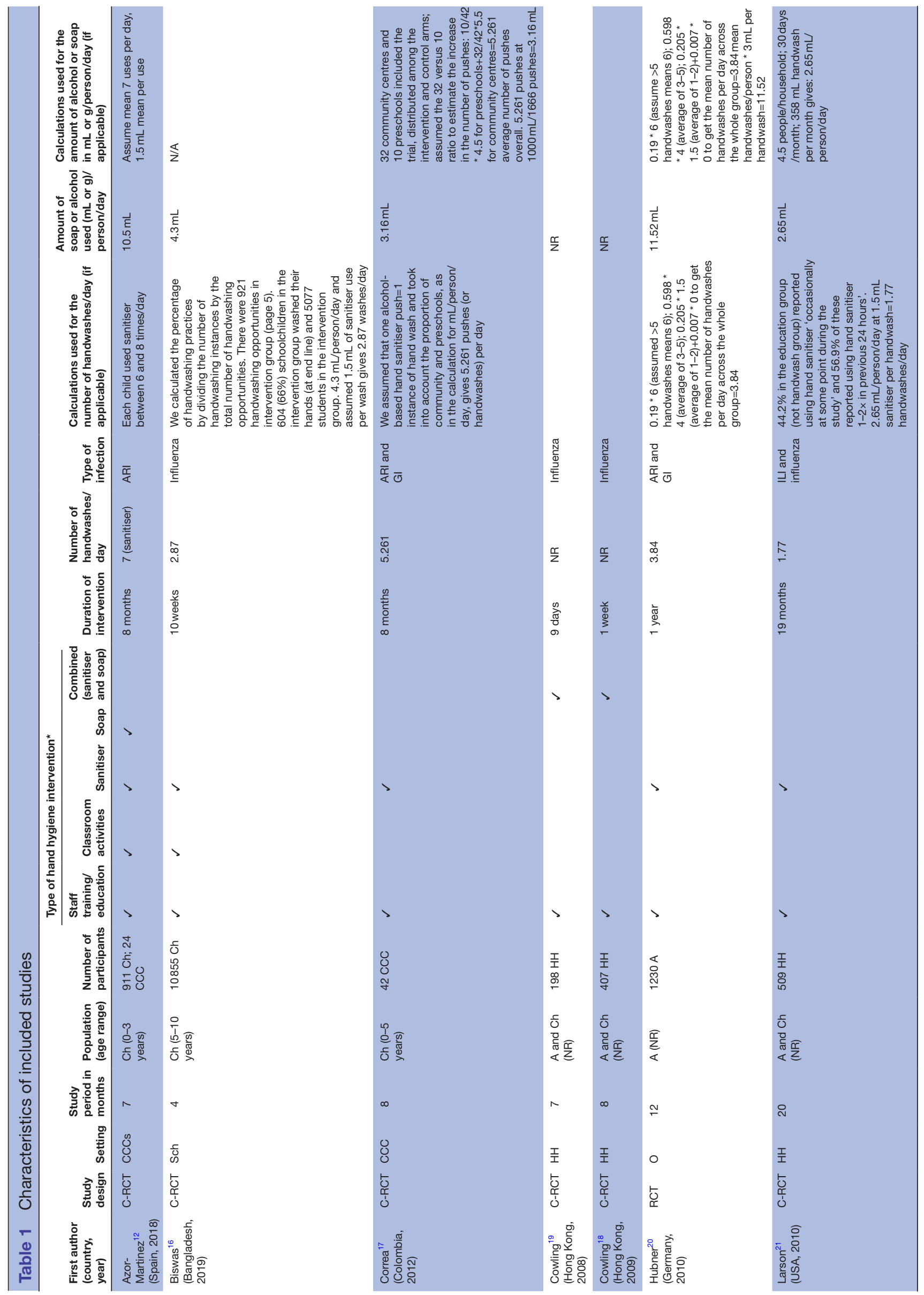

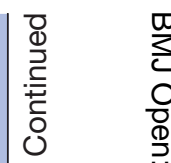




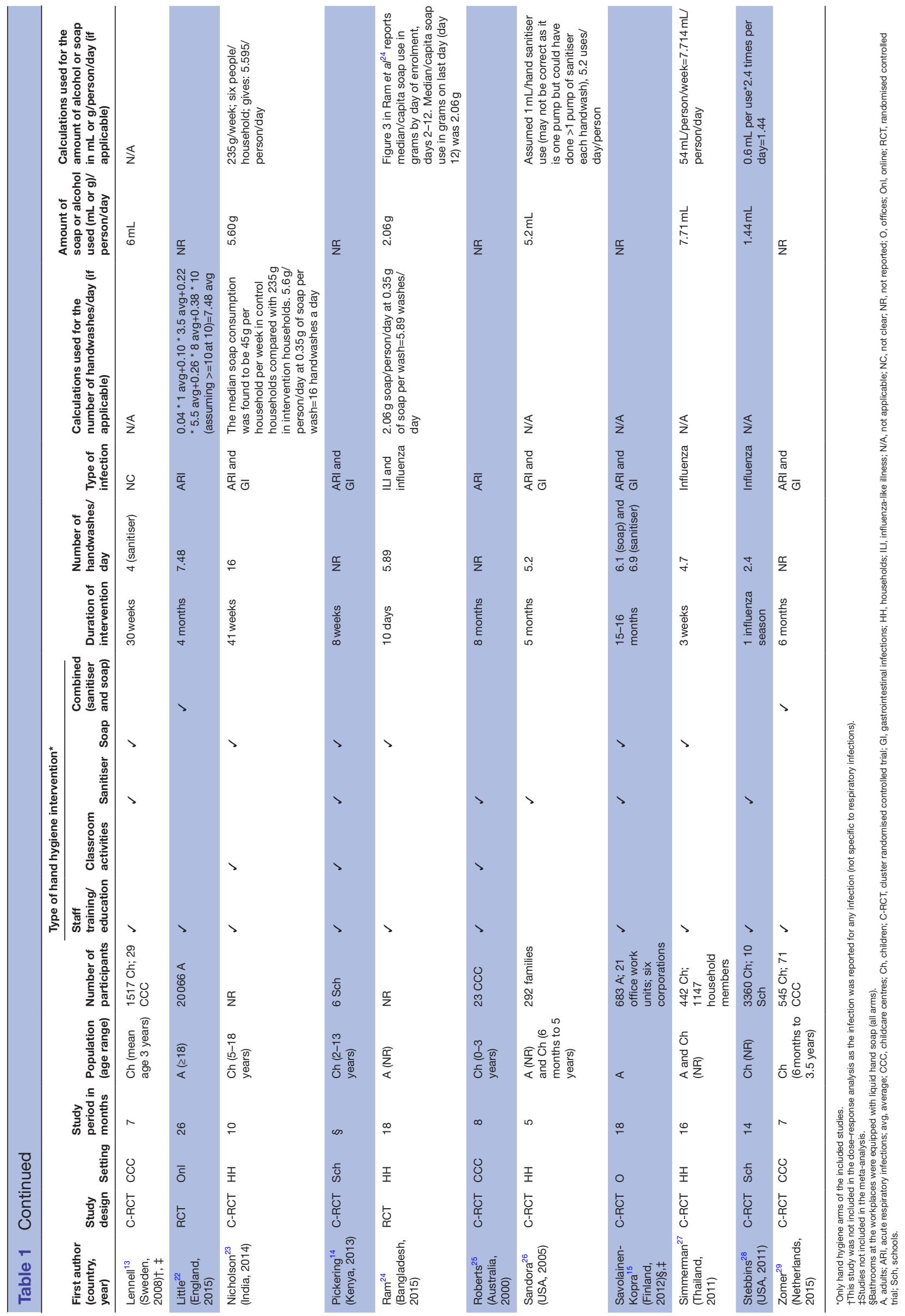

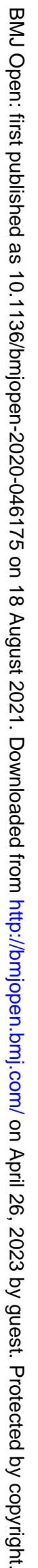


number of events (eg, ARI events) in each group irrespective of the number per person. We contacted investigators to provide missing data where feasible. We used the $\mathrm{I}^{2}$ statistic to measure heterogeneity among the included trials. We referred to the Cochrane Handbook in the interpretation of the $\mathrm{I}^{2}$ statistic and were guided by the following ranges: $0 \%-40 \%$ : may represent non-significant heterogeneity; 30\%-60\%: may represent moderate heterogeneity; 50\%-90\%: may represent substantial heterogeneity; $75 \%-100 \%$ : considerable heterogeneity. ${ }^{11}$ Data were sufficient to conduct a subgroup analysis by comparison (soap vs sanitiser vs combination soap and sanitiser). To ensure we accounted for the clustering effect in the cluster RCTs, we extracted the appropriate cluster-adjusted estimates from the trial reports and used the generic inverse variance method of meta-analysis.

\section{Patient and public involvement}

Patients or the public were not involved in the design, or conduct, or reporting, or dissemination plans of our research.

\section{RESULTS}

The Preferred Reporting Items for Systematic Reviews and Meta-Analyses flow chart (figure 1) shows the number of trials identified from the 2020 parent systematic review ${ }^{5}$ and other sources. Eighteen trials were assessed as eligible;

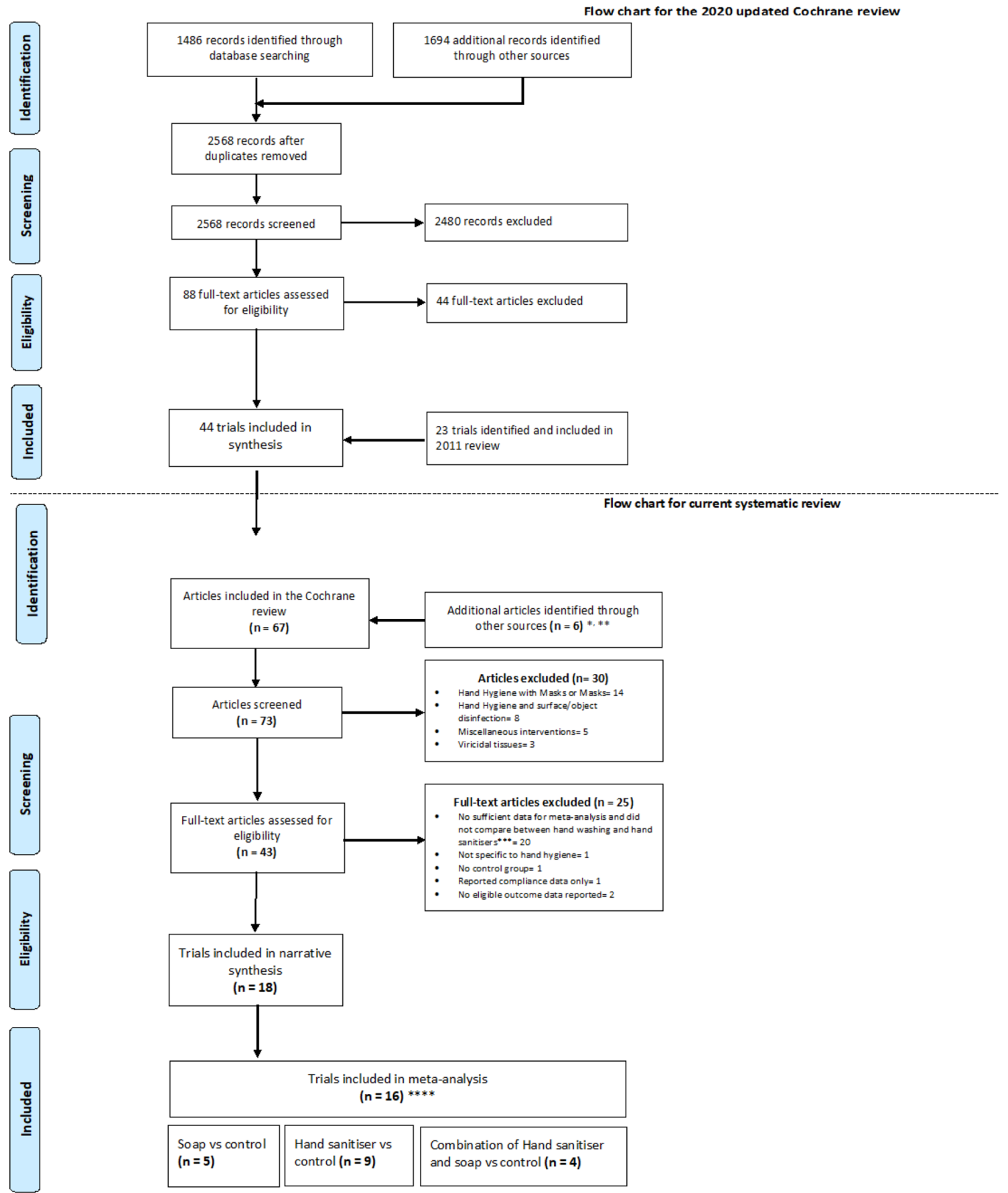

Figure 1 PRISMA flow chart. PRISMA, Preferred Reporting Items for Systematic Reviews and Meta-Analyses. 


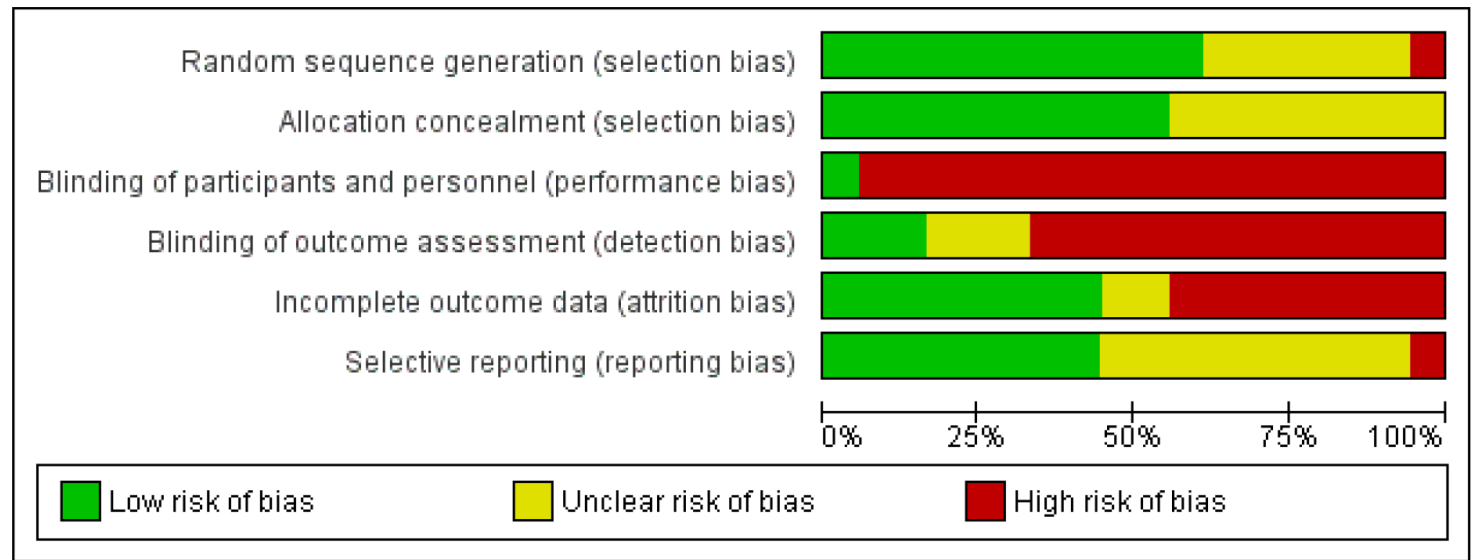

Figure 2 Overall risk of bias - presented as percentages across all included RCTs. RCTs, randomised controlled trials.

four were head-to-head comparisons of hand sanitiser and soap and water ${ }^{12-15}$ and 16 compared hand hygiene with a control. ${ }^{14} 16-29$ Table 1 presents study and intervention characteristics. Online supplemental file 2 contains a summary of the comparator conditions. The majority of trials used existing handwashing practices as the comparator condition. One trial additionally provided education on hand hygiene, and four provided health promotion education and provided participants with education on the prevention and treatment of respiratory tract infections. None of the studies provided control group participants with any hand hygiene materials.

\section{Risk of bias assessment}

Most studies (95\%) were unblinded due to the nature of the intervention, leading to a high risk of bias judgement (figure 2). See online supplemental file 3 for risk of bias assessment for each individual trial. Only one study was blinded to staff. ${ }^{27}$ Blinding of outcome assessment and attrition bias was poor across $67 \%$ and $44 \%$ of studies, respectively. Sequence generation and allocation concealment had a low risk of bias assessment in about half of the studies. Fifty per cent of studies had unclear risk of bias for selective outcome reporting due to the lack of sufficient information.

\section{Trials of hand sanitiser or soap and water versus control}

Figure 3A presents the meta-analysis of all trials, regardless of whether the number of handwashes could be estimated. Combining the five trials of soap and water hand hygiene versus control found a non-significant increase in ARI events: RR: 1.03 (95\% CI 0.86 to 1.23 ) but with high heterogeneity. The nine trials of hand sanitiser versus control found a significant reduction in ARI events: RR: 0.85 (95\% CI 0.77 to 0.94 ), providing some indirect evidence in favour of hand sanitiser.

A similar pattern of results was found when only trials for which the number of handwashes could be estimated were considered (figure 3B), combining the three trials of soap and water hand hygiene versus control found a non-significant increase in ARI events: RR: 1.23 (95\% CI

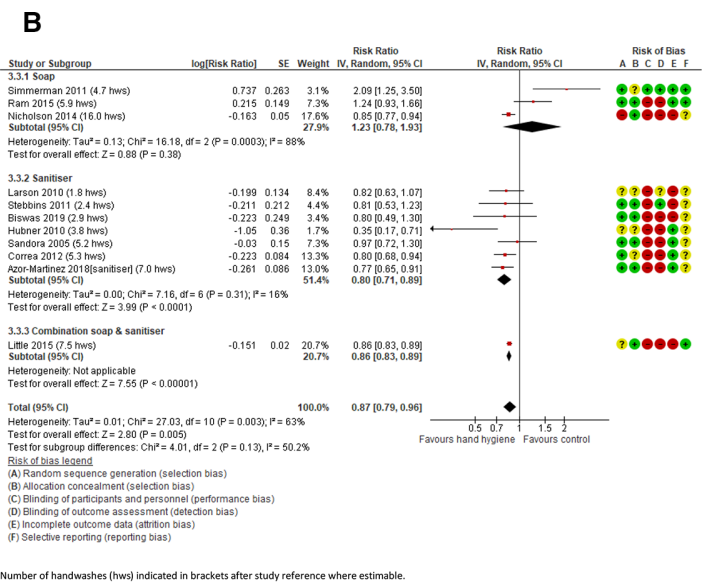

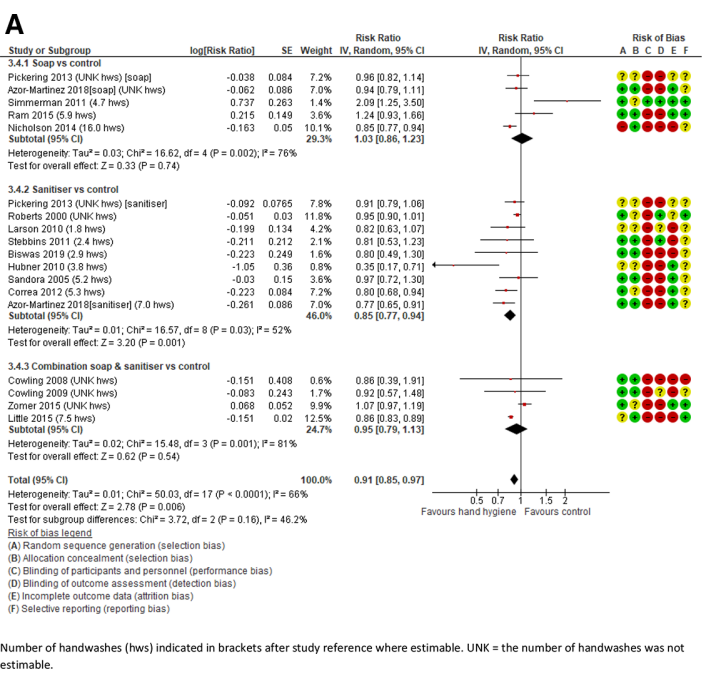

Figure 3 (A) Meta-analysis of all studies (regardless of whether the number of handwashes could be estimated) regardless of the type of handwash material (soap vs sanitiser vs combination of sanitiser and soap). (B) Meta-analysis of studies whose number of handwashes could be estimated, subgrouped by the type of handwash material (soap vs sanitiser vs combination of sanitiser and soap). 


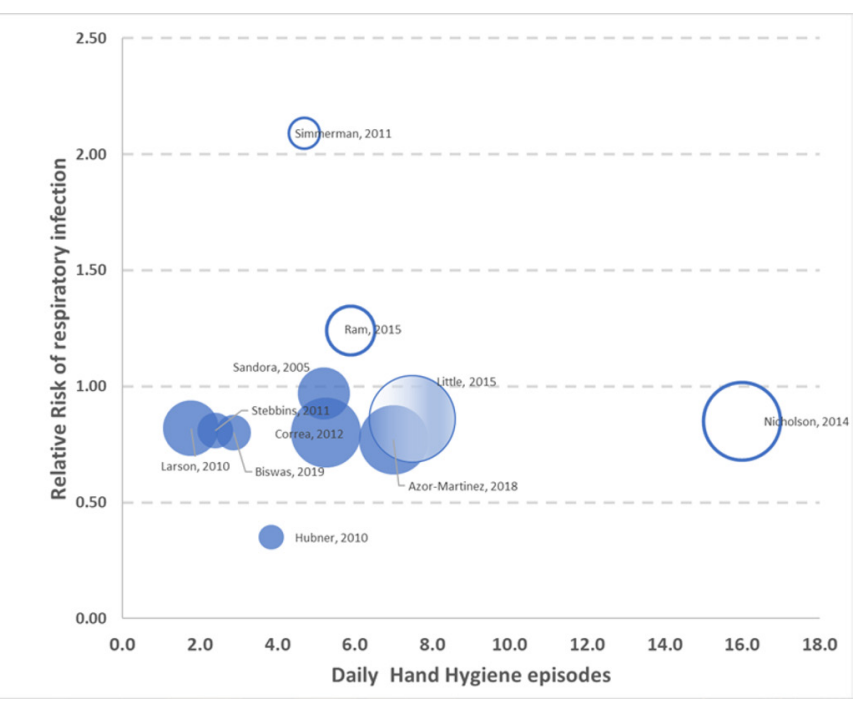

Figure 4 Hand hygiene frequency ('dose') versus risk of respiratory infection (ARI, ILI or influenza). ARI, acute respiratory infection; ILI, influenza-like illness.

0.78 to 1.93 ) but with high heterogeneity (figure 3B). Combining the seven trials of hand sanitiser versus control found a significant reduction in ARI events: RR: 0.80 (95\% CI 0.71 to 0.89 ).

Dose-response relationship: hand hygiene frequency versus risk of respiratory infection (ARI, ILI or influenza)

Eleven of the trials provided sufficient information to estimate the dose of hand hygiene, which we converted to number of hand hygiene events per day. Plotted against the relative risk of ARIs, there is little dose-response relationship evident for hand sanitiser (figure 4). The difference in effectiveness between hand sanitiser and soap and water does not appear to be explained by a difference in frequency. The cluster randomised trial by Little and colleagues ${ }^{22}$ primarily used soap and water but also offered participants free hand sanitiser; only $18 \%$ reported collecting the sanitiser.

\section{Head-to-head trials of hand hygiene with hand sanitiser versus with soap and water}

Four trials directly compared hand sanitiser with soap and water: two in childcare centres, one at a primary school and one in workplaces. In a cluster randomised trial of children and staff in Swedish childcare centres, those at centres who were randomised to use an alcohol-based oily disinfectant gel (70\% ethanol) after regular hand washing had a reduction in absenteeism rate of $12 \%$ (95\% CI $4 \%$ to $20 \%$ ) compared with control centres which used only soap and water. ${ }^{13}$ The three-arm cluster randomised trial of 24 childcare centres in Spain: educational and hand hygiene measures (one with soap and water; another with hand sanitiser) and a control group found children in the sanitiser group had a $13 \%$ lower (95\% CI 6\% to 28\%) risk of respiratory infection than children in the soap and water group. ${ }^{12}$

In Kenya, a cluster randomised trial assigned two primary schools to receive a handwashing with soap and water intervention, two to receive a sanitiser intervention and two were a control. ${ }^{14}$ Compared with control group students, both intervention groups had a reduction in observed rhinorrhoea (RR $0.77,95 \%$ CI 0.62 to 0.95 for both sanitiser vs control and soap vs control). No significant differences between the sanitiser and soap groups were observed for respiratory outcomes. The three-arm trial in six companies in Finland randomised workplaces to equip workplace bathrooms with liquid hand soap (soap and control arms) or alcohol-based hand rub. ${ }^{15}$ Participants in the intervention arms also received guidance on additional strategies for limiting infection transmission. Before the onset of the 2009 influenza pandemic (and the subsequent national hand hygiene campaign), a statistically significant $(\mathrm{p}=0.002)$ difference in the infection episodes was observed between the control (6.0 per year) and the soap-and-water arm (5.0 per year) but not between the control and the alcohol rub arm (5.6 per year). Neither intervention had an effect on work absenteeism.

\section{DISCUSSION}

Based on both indirect and direct (head to head) trials, hand hygiene using alcohol-based hand sanitiser appears more effective at reducing ARI transmission than hand hygiene using soap and water, with the difference in effect not explained by the difference in frequency of hand hygiene. This is an important finding, as most guidelines consider the two hand hygiene processes as equivalent, based on microbiological data for correctly performed processes.

The apparent greater effectiveness of hand sanitiser may be explained by its greater convenience, the lesser time required to perform hand hygiene, more sustained compliance with hand hygiene and less irritation to the skin. ${ }^{30}$ From our review of current research, we cannot determine the relative contribution of these behavioural elements, and hence further research is warranted to examine those contributions and ways to improve each.

Limitations of this review are that conclusions are mostly from indirectness evidence, with direct evidence available from only four head-to-head trials and that it was not possible to estimate the dose of hand hygiene for some trials. The variable duration of the interventions (which ranged from 2 to 26 months) in the included studies may have impacted the reported intervention adherence and hence the comparability of it.

A recent Cochrane review of the effect of rinse-free handwashing, compared with traditional hand hygiene, on absenteeism for ARI in preschool and school children reported a significant reduction in absenteeism of 9 days per 1000 available days for children in the rinse-free group, with the results coming from six randomised trials. ${ }^{9}$ The effectiveness of handwashing with materials other than sanitiser or soap and water, such as ash, which may be used in low-income countries, has mostly been examined in observational studies with uncertain effects. ${ }^{31}$ 
Although the current evidence modestly favours hand sanitiser, further trials of hand hygiene methods are warranted. Any such trials should include a set of process measures looking at the 'intervention fidelity' elements, such as frequency and correctness of hand hygiene processes. Meanwhile, policy documents and public guidance should continue to suggest both but indicate that current evidence somewhat favours sanitiser for behavioural rather than biological reasons and that it should be recommended where feasible.

\section{CONCLUSIONS}

Hand hygiene has a modest but important role in reducing the transmission of ARIs. Adequately performed hand hygiene, with either soap or sanitiser, reduces the risk of acute respiratory virus transmission. However, from both the direct and indirect comparisons in this review, sanitiser appears more effective in practice. While further head-to-head randomised trials are warranted, the current evidence appears sufficient to promote the use of hand sanitiser as the primary means for many everyday situations.

\section{Twitter Tammy Hoffmann @Tammy_Hoffmann and Mina Bakhit @Mina_Bakhit}

Acknowledgements We would like to acknowledge the authors of the 2020 Cochrane review update (L AlAnsary, G Bawazeer, E Beller, J Clark, J Conly, E Dooley, E Ferroni, T Jefferson, S Thorning, M van Driel and M Jones).

Contributors TH, PG and CDM conceived the study. MB and NK screened studies for inclusion in this review and extracted the data. TH, AMS, PG and CDM analysed the data. TH wrote the first draft. All authors approved and revised the final manuscript.

Funding The authors have not declared a specific grant for this research from any funding agency in the public, commercial or not-for-profit sectors.

Competing interests None declared.

Patient consent for publication Not required.

Provenance and peer review Not commissioned; externally peer reviewed.

Data availability statement All data relevant to the study are included in the article or uploaded as supplemental information.

Supplemental material This content has been supplied by the author(s). It has not been vetted by BMJ Publishing Group Limited (BMJ) and may not have been peer-reviewed. Any opinions or recommendations discussed are solely those of the author(s) and are not endorsed by BMJ. BMJ disclaims all liability and responsibility arising from any reliance placed on the content. Where the content includes any translated material, BMJ does not warrant the accuracy and reliability of the translations (including but not limited to local regulations, clinical guidelines, terminology, drug names and drug dosages), and is not responsible for any error and/or omissions arising from translation and adaptation or otherwise.

Open access This is an open access article distributed in accordance with the Creative Commons Attribution Non Commercial (CC BY-NC 4.0) license, which permits others to distribute, remix, adapt, build upon this work non-commercially, and license their derivative works on different terms, provided the original work is properly cited, appropriate credit is given, any changes made indicated, and the use is non-commercial. See: http://creativecommons.org/licenses/by-nc/4.0/.

\section{ORCID iDs}

Tammy Hoffmann http://orcid.org/0000-0001-5210-8548

Mina Bakhit http://orcid.org/0000-0002-6162-3362

Natalia Krzyzaniak http://orcid.org/0000-0001-5668-7292

Chris Del Mar http://orcid.org/0000-0003-3821-8163

Anna Mae Scott http://orcid.org/0000-0002-0109-9001

Paul Glasziou http://orcid.org/0000-0001-7564-073X
REFERENCES

1 Ferkol T, Schraufnagel D. The global burden of respiratory disease. Ann Am Thorac Soc 2014;11:404-6.

2 World Health Organization. WHO coronavirus disease (COVID-19) dashboard, 2021. Available: https://covid19.who.int/?gclid=EAlalQob ChMI8Y7YwLqS7AIVmraWCh0sngONEAAYASAAEgKucPD_BwE; [Accessed 01 Apr 2021].

3 Wong VWY, Cowling BJ, Aiello AE. Hand hygiene and risk of influenza virus infections in the community: a systematic review and meta-analysis. Epidemiol Infect 2014;142:922-32.

4 Carcione D, Giele CM, Goggin LS, et al. Secondary attack rate of pandemic influenza A(H1N1)2009 in Western Australian households, 29 May-7 August 2009. Eurosurveillance 2011;16:pp. 19765.

5 Jefferson Tet al. Physical interventions to interrupt or reduce the spread of respiratory viruses. Cochrane Database of Syst Rev 2020;11.

6 Jefferson T, Del Mar CB, Dooley L, et al. Physical interventions to interrupt or reduce the spread of respiratory viruses. Cochrane Database Syst Rev 2011;141.

7 Clark JM, Sanders S, Carter M, et al. Improving the translation of search strategies using the polyglot search translator: a randomized controlled trial. J Med Libr Assoc 2020;108:195-207.

8 Marshall IJet al. Machine learning for identifying randomized controlled trials: an evaluation and practitioner's guide. Res Synth Methods 2018;9:602-14. doi:10.1002/jrsm.1287

9 Munn Z, Tufanaru C, Lockwood C, et al. Rinse-free hand wash for reducing absenteeism among preschool and school children. Cochrane Database Syst Rev 2020;4:CD012566. doi:10.1002/14651858.CD012566.pub2

10 Koehler A, Wildbolz C. Comparing the environmental footprints of home-care and personal-hygiene products: the relevance of different life-cycle phases. Environ Sci Technol 2009;43:8643-51.

11 Higgins JPTet al. Cochrane handbook for systematic reviews of interventions version 6.0. Cochrane database of systematic reviews 2019 www.training.cochrane.org/handbook;

12 Azor-Martinez E, Yui-Hifume R, Muñoz-Vico FJ, et al. Effectiveness of a hand hygiene program at child care centers: a cluster randomized trial. Pediatrics 2018;142. doi:10.1542/peds.2018-1245. [Epub ahead of print: 08102018 ]

13 Lennell A, Kühlmann-Berenzon S, Geli P, et al. Alcohol-based handdisinfection reduced children's absence from Swedish day care centers. Acta Paediatr 2008;97:1672-80.

14 Pickering AJ, Davis J, Blum AG, et al. Access to waterless hand sanitizer improves student hand hygiene behavior in primary schools in Nairobi, Kenya. Am J Trop Med Hyg 2013;89:411-8.

15 Savolainen-Kopra C, Haapakoski J, Peltola PA, et al. Hand washing with soap and water together with behavioural recommendations prevents infections in common work environment: an open clusterrandomized trial. Trials 2012;13:10.

16 Biswas D, Ahmed M, Roguski K, et al. Effectiveness of a behavior change intervention with hand sanitizer use and respiratory hygiene in reducing laboratory-confirmed influenza among schoolchildren in Bangladesh: a cluster randomized controlled trial. Am J Trop Med Hyg 2019;101:1446-55.

17 Correa JC, Pinto D, Salas LA, et al. A cluster-randomized controlled trial of handrubs for prevention of infectious diseases among children in Colombia. Rev Panam Salud Publica 2012;31:476-84.

18 Cowling BJ, Chan K-H, Fang VJ, et al. Facemasks and hand hygiene to prevent influenza transmission in households: a cluster randomized trial. Ann Intern Med 2009;151:437-46.

19 Cowling BJ, Fung ROP, Cheng CKY, et al. Preliminary findings of a randomized trial of non-pharmaceutical interventions to prevent influenza transmission in households. PLoS One 2008;3:e2101.

20 Hübner N-O, Hübner C, Wodny M, et al. Effectiveness of alcoholbased hand disinfectants in a public administration: impact on health and work performance related to acute respiratory symptoms and diarrhoea. BMC Infect Dis 2010;10:250.

21 Larson EL, Ferng Y-hui, Wong-McLoughlin J, et al. Impact of nonpharmaceutical interventions on URIs and influenza in crowded, urban households. Public Health Rep 2010;125:178-91.

22 Little P, Stuart B, Hobbs FDR, et al. An internet-delivered handwashing intervention to modify influenza-like illness and respiratory infection transmission (PRIMIT): a primary care randomised trial. Lancet 2015;386:1631-9.

23 Nicholson JA, Naeeni M, Hoptroff M, et al. An investigation of the effects of a hand washing intervention on health outcomes and school absence using a randomised trial in Indian urban communities. Trop Med Int Health 2014;19:284-92.

24 Ram PK, DiVita MA, Khatun-e-Jannat K, et al. Impact of intensive handwashing promotion on secondary household influenza-like illness in rural Bangladesh: findings from a randomized controlled trial. PLoS One 2015;10:p. e0125200. 
25 Roberts L, PhD Epid,, Smith W, Jorm L, et al. Effect of infection control measures on the frequency of upper respiratory infection in child care: a randomized, controlled trial. Pediatrics 2000;105:738-42.

26 Sandora TJ, Taveras EM, Shih M-C, et al. A randomized, controlled trial of a multifaceted intervention including alcohol-based hand sanitizer and hand-hygiene education to reduce illness transmission in the home. Pediatrics 2005;116:587-94.

27 Simmerman JM, Suntarattiwong P, Levy J, et al. Findings from a household randomized controlled trial of hand washing and face masks to reduce influenza transmission in Bangkok, Thailand. Influenza Other Respir Viruses 2011:5:256-67.
28 Stebbins S, Cummings DAT, Stark JH, et al. Reduction in the incidence of influenza A but not influenza B associated with use of hand sanitizer and cough hygiene in schools: a randomized controlled trial. Pediatr Infect Dis J 2011;30:921-6.

29 Zomer TP, Erasmus V, Looman CW, et al. A hand hygiene intervention to reduce infections in child daycare: a randomized controlled trial. Epidemiol Infect 2015;143:2494-502.

30 Pittet $\mathrm{D}$. Improving adherence to hand hygiene practice: a multidisciplinary approach. Emerg Infect Dis 2001;7:234-40.

31 Paludan-Müller AS, Boesen K, Klerings I, et al. Hand cleaning with ash for reducing the spread of viral and bacterial infections: a rapid review. Cochrane Database Syst Rev 2020;4:CD013597. 